\title{
Settlements Preparation for Future Progress in Vehicles
}

\author{
Hasenko LV* and Lytvynenko TP \\ Department of Highways, Geodesy, Land Management and Rural Buildings, National University Yuri Kondratyuk Poltava Polytechnic, Ukraine
}

Submission: February 19, 2020; Published: July 07, 2020

*Corresponding author: Hasenko LV, Department of Highways, Geodesy, Land Management and Rural Buildings, National University Yuri Kondratyuk Poltava Polytechnic, Ukraine

Abstract

The research is devoted to individual environment-friendly vehicles, which can be used in the street-road network of settlements. Are analyzed the benefits that accrue from the use of such vehicles in the areas of medicine, the environment, the economy, and the social sphere. The examples of individual vehicles, the most common of which is a bicycle, are presented. Are formulated particularities of such modes of transport and the requirements that must be applied to the infrastructure for comfortable and safe driving by them.

Keywords: Individual environment-friendly vehicles, Street and road network, Design principles.

Abbreviations: IEFV - individual environment-friendly vehicles, SRN - street and road network.

\section{Introduction}

The settlements infrastructure development, aimed at satisfying, first, the needs of motorists, is accompanied by powerful negative changes in the conditions of human life [1]. Recently, more and more researchers of transport planning use the term «Automobile Dependency» [2]. In developed countries, alternative vehicles are becoming increasingly popular - individual (for 1 or 2 people) eco-friendly (do not harm the environment) vehicles [3]. This article discusses the principles of creating infrastructure for the movement of IEVF (the most common of which is currently a bicycle) into the street and road network of settlements.

\section{Discussion}

World experience shows that even investing heavily in the road network development, the solution of road transport services complex problems, it is impossible to solve the problem of transportation in large cities by providing comfortable movement of cars. Not by chance the best in terms of transport cities in the world (Copenhagen, Berlin and others) use the socalled pyramid of priority (Figure 1), which advise to apply when making decisions in SRN designing and reconstruction [4].

Considering the mass of the pedestrian movement (almost every citizen with one or another frequency use to move the walking) and its safety for the environment, on the highest step of this pyramid put pedestrians. On the second step is cycling transport, which has the same advantages and problems as the pedestrian, but occupies a separate place in the pyramid because it allows you to overcome much larger distances (effective radius of bicycle use is $5-7 \mathrm{~km}$ ) and needs parking spaces and, on separate streets, a separate infrastructure.

In our opinion, the creation of infrastructure for bicycle traffic is the preparation of settlements for future progress in the field of vehicles. Since scientists of the world are now actively working on the creation of various types of IEFV designed to replace or minimize the use of individual cars in settlements. For example, in the countries of Europe and America Segway is already actively used - an individual vehicle, which is a small platform on two wheels with an electric motor (Figure 2a). It is controlled by moving the centre of weight [5].

The press service of Segway-Ninebot published the announcement of a new vehicle. An unusual model of a hovercraft called S-Pod is a comfortable egg-shaped chair (Figure 2b). The S-Pod is based on the same gyroscopic self-balancing system as the company's previous products. Unlike all other models, control is carried out using a manual joystick on the armrest [6].

YikeBike - the little electric bike (Figure 2c) that has 450-watt motor that will take you for six miles at $14 \mathrm{mph}$, built-in LED lights and anti-skid regenerative brakes [7]. Recently e-scooters (Figure 


\section{Civil Engineering Research Journal}

2d) have become a common sight in many cities in the US and Europe [8]. So, among the features that combine the above IEVF and other similar modes of transport, the following advantages and disadvantages can be distinguished.

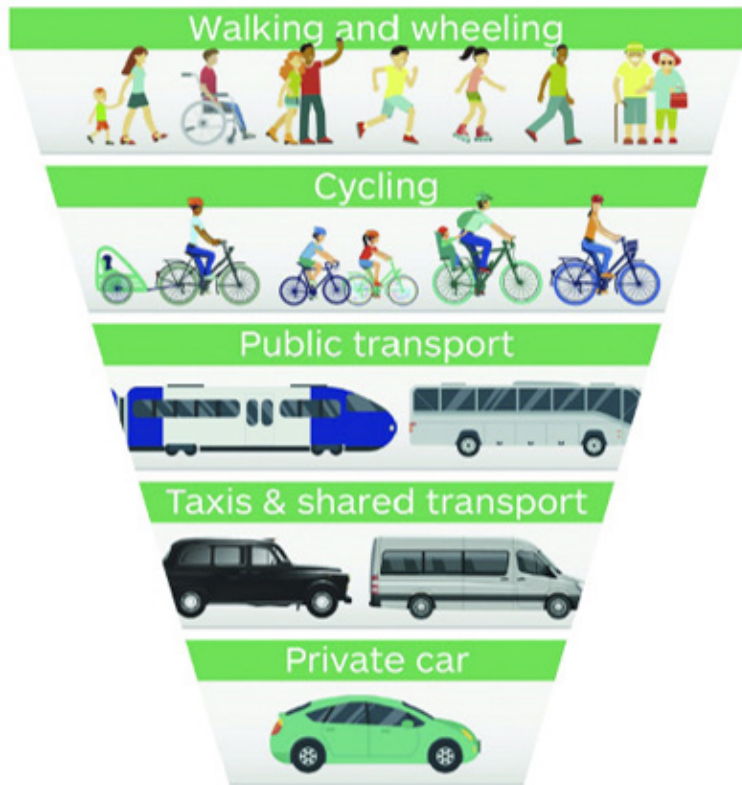

Figure 1: Prioritizing sustainable transport.
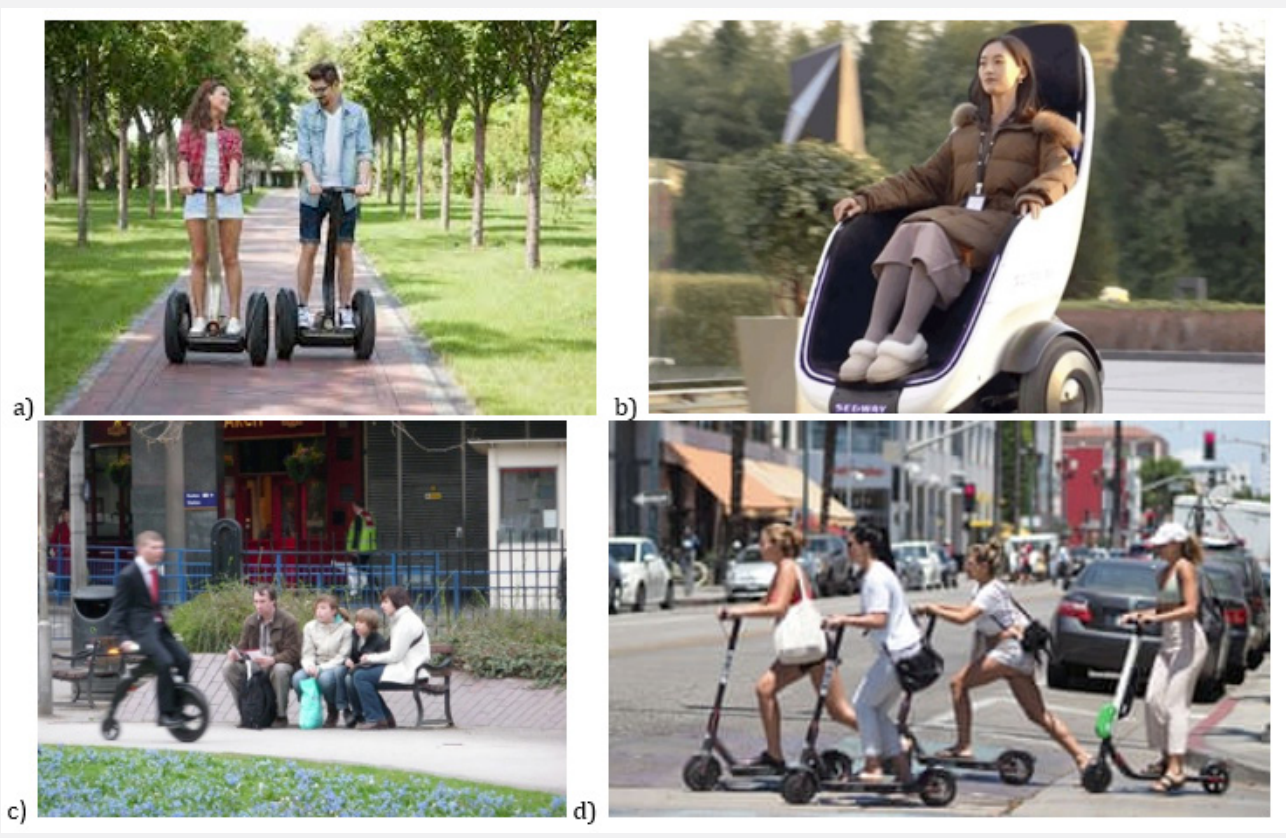

Figure 2: Individual vehicles: a) Segway; b) S-Pod; c) Yike Bike; d) e-scooters.

\section{Advantages}

a. environmental friendliness: the use of such modes of transport does not harm the environment and does not create noise. b. compactness: such modes of transport occupy much less space than cars on roads and parking lots.

c. mobility: in places where a car with its dimensions cannot pass, the IEFV often drives without inconvenience. 


\section{Civil Engineering Research Journal}

\section{Disadvantages}

a) low speed of movement in comparison with the car.

b) instability: the area of the IEFV contact with the road surface is smaller than that of the car, which leads to less stability of the IEFV.

c) insecurity of a driver from precipitation.

Based on the above properties of IEFV, we can formulate the features of infrastructure design for the movement of such vehicles:

1) When designing such an infrastructure, care should be taken to protect the driver of an environmentally friendly vehicle from harmful exhaust gases from cars and the noise they generate.

2) The compactness and mobility of the IEFV allow you to design ways for driving on them in those places where area restrictions do not allow to lay roads.

3) The relatively low speed of IEFV requires the shortest means of communication, which will allow you to reach the final points within the time limit not exceeding automobile crossings, as well as the completeness and consistency of routes.

4) Based on the small area of IEFV contact with the road, special attention should be paid to the evenness, roughness and adhesion of the road surfaces.

5) Since most IEFV do not provide driver protection from precipitation, this must be considered when designing the infrastructure. So, it can be installed special canopies over bike paths in front of traffic lights, in bicycle parking lots and in bike rental locations.

\section{Conclusion}

The use of individual eco-friendly vehicles in the street-road structure of a settlement brings with it a number of positive changes. To date, the most common type of IEFV is a bicycle. The introduction of bicycle infrastructure into the SRN not only solves many problems of modern settlements, but also prepares them for future progress in the field of vehicles. When designing the infrastructure for the IEFV traffic, it is necessary to protect the drivers of such vehicles from car noise, gas pollution and precipitation, if possible. Particular attention should be paid to coatings used on the IEFV traffic routes. Routes should be short, complete and logical. So, to ensure the comfortable movement of the IEVF, in addition to laying special routes (complex, with road connections, convenient exits, comfortable coverage), a number of issues still need to be addressed:- to organize traffic (to set up traffic signs, traffic lights, to provide "green waves", to build special tunnels, overpasses, junctions, etc., to coordinate the intersection of paths for IEFV traffic with passenger boarding and landing points for public transport) to create infrastructure for IEFV (to develop a rental system for such vehicles, to arrange convenient parking, to build service stations) to provide social protection for IEFV drivers (to regulate their rights as full-fledged participants in road traffic, to ensure the possibility of transporting small vehicles in public transport) to coordinate the work of public utilities (to organize the work of snow machines and constant monitoring of the cleanliness and serviceability of such paths).

\section{Acknowledgement}

The work is connected with the research program of Highways, Geodesy, Land management and Rural buildings department of National University «Yuri Kondratyuk Poltava Polytechnic» (Ukraine) -“Improvement of highways and street and road network" (Project ID: 0114U000354).

\section{References}

1. Litvinenko T, Hasenko L and Ivasenko V (2019) Design principles of inclusive street-road environment. Mechanisms for Ensuring Sustainable Development of Society. Collective Scientific Monograph, Katowice School of Technology pp: 203-217.

2. Barton H, Tsourou C (2000) Healthy Urban Planning. WHO Regional Office for Europe. London \& New York, Spon Press pp: 212.

3. Carreno M, Ying-En G and Borthwick S (2014) Could green taxation measures help incentivize future Chinease car drivers to purchase low emission vehicles?, Transport. 29 (3): 260-268.

4. Chris Ames (2019) Getting to the point of inverted priorities. Highways Magazine masthead.Online resource: https://www.highwaysmagazine. co.uk/Getting-to-the-point-of-inverted-priorities/5256

5. Openbusiness.ru (2019) How to open a Segway rental business. Online resource:

https://www.openbusiness.ru/biz/business/kak-otkryt-biznes-poprokatu-segway/

6. Segway (2020) S-Pod: Segway showed a scooter chair inspired by the Gyrosphere of the Jurassic World. Eco-friendly technology. Online resource:

https://ecotechnica.com.ua/transport/4556-s-pod-segway-pokazalakreslo-skuter-vdokhnovlennoe-girosferoj-mira-yurskogo-perioda. html

7. Charlie Sorrel (2011) Yike Bike Mini-Farthing Gets Cheaper, Heavier Brother. Wired. Online resource:

https://translate.google.com.ua/?tl=fr\#view=home\&op=translate\&sl=en $\& \mathrm{tl}=\mathrm{ru} \&$ text=Wired

8. James Tapper (2019) Coming to a street near you? UK's e-scooter road ban set to end. The Observer. Transport. Online resource:

https://www.theguardian.com/uk-news/2019/mar/09/electricscooters-uk-road-ban-set-to-end 
(C) This work is licensed under Creative Commons Attribution 4.0 License DOI: 10.19080/CERJ.2020.10.555781
Your next submission with Juniper Publishers will reach you the below assets

- Quality Editorial service

- Swift Peer Review

- Reprints availability

- E-prints Service

- Manuscript Podcast for convenient understanding

- Global attainment for your research

- Manuscript accessibility in different formats

( Pdf, E-pub, Full Text, Audio)

- Unceasing customer service

Track the below URL for one-step submission https://juniperpublishers.com/online-submission.php 